\title{
A COMPARATIVE ANALYSIS OF FUZZY BASED HYBRID ANFIS CONTROLLER FOR STABILIZATION AND CONTROL OF NON- LINEAR SYSTEMS
}

\author{
Ashwani Kharola \\ $\mathrm{PhD}$ Scholar, Department of Mechanical Engineering, Graphic Era University, Dehradun \\ Senior Research Fellow (SRF), Institute of Technology Management (ITM) \\ Defence Research \& Development Organization (DRDO), Landour Cantt Mussoorie
}

\begin{abstract}
This paper illustrates a Comparative study of highly non-linear, complex and multivariable Inverted Pendulum (IP) system on Cart using different soft computing techniques. Firstly, a Fuzzy logic controller was designed using triangular and trapezoidal shape Membership functions (MF's). The trapezoidal fuzzy controller shows better results in comparison to triangular fuzzy controller. Secondly, an Adaptive neuro fuzzy inference system (ANFIS) controller was used to optimize the results obtained from trapezoidal fuzzy controller. Finally, the study illustrates the effect of variation in shape of $M F^{\prime}$ 's on Performance parameters of the IP system. The results shows that ANFIS controller provides better results in comparison to both fuzzy controller.
\end{abstract}

\section{KEYWORDS}

Inverted Pendulum, Fuzzy logic, ANFIS, Performance parameters, Matlab-Simulink.

\section{INTRODUCTION TO INVERTED PENDULUM}

Inverted Pendulum(IP) systems belongs to a class of highly non-linear and complex systems which act as testing bed for many unstable systems[1]. The control and stabilization of IP at upright position is one of the most challenging problem in the field of control engineering since 1950s[7,8]. IP finds many applications in following control techniques including feedback stabilization[2], friction compensation[3], hybrid control[4], back stepping control[5] etc.

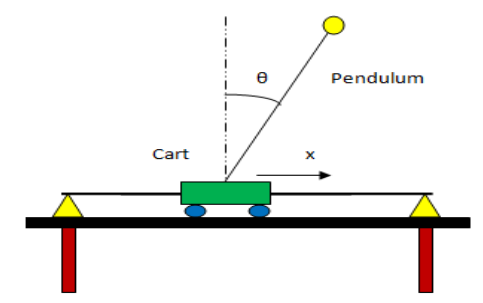

Figure 1.0 Inverted Pendulum on Cart

DOI: $10.14810 / \mathrm{ijscmc} .2015 .4402$ 
A view of IP on Cart is shown in Fig 1.0.[6]. The Cart is driven by electric motor while a pendulum freely pivoted to it. The pendulum is highly unstable and falls in case of any disturbance. The IP system has two equilibrium; one is stable while the other is unstable. In case of the stable equilibrium position, the pendulum is pointing downwards. In absence of any control force, the system will be in this state. In unstable equilibrium pendulum points strictly upwards and, thus, requires a control force to maintain this position. The control objective of this study is to maintain the unstable equilibrium position when the pendulum initially starts in an upright position [15]. The dynamics of inverted pendulum is quite similar to two-wheeled mobile robots [9,10], flexible link robot [11], biped robot limbs [12,13], missiles [14] etc.

\section{DERIVATION OF GOVERNING MATHEMATICAL EQUATIONS FOR IP SYSTEM}

The IP system consists of a pendulum of mass, $\mathrm{m}$, pivoted to a cart of mass, M. The pendulum is inclined at an angle, $\theta$ from vertical axis as shown in figure 1.1. A force, $\mathrm{F}$ is required to push the cart horizontally, the coefficient of friction, $b$, length of pendulum $\mathrm{L}$ and the second moment of inertia for pendulum, I [16].

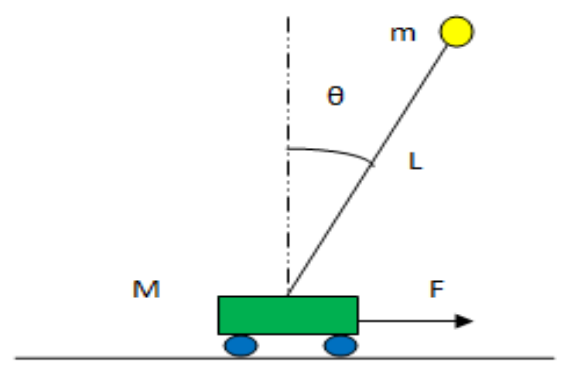

Figure 1.1 Diagram of Inverted Pendulum

For modelling and simulation of IP system the following dynamic equations are derived using Free body diagrams (FBD) of cart and pendulum sub-systems [17]. A view of FBD of cart and pendulum are shown in figure 1.2 and figure 1.3 respectively.

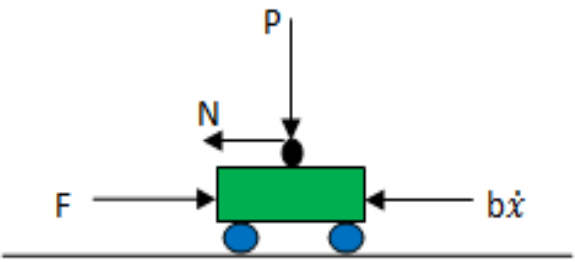

Figure 1.2 FBD of Cart Sub-system

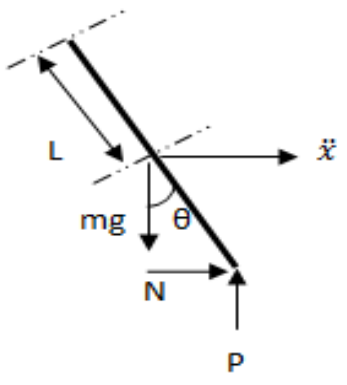

Figure 1.3 FBD of Pendulum Sub-system 
The various parameters of IP system considered for this study are shown in the table 1.0.[23]

\begin{tabular}{|c|c|}
\hline Parameter & Magnitude \\
\hline Mass of Cart (M) & $1.0 \mathrm{~kg}$ \\
\hline Mass of Pendulum (m) & $0.5 \mathrm{~kg}$ \\
\hline Length of Pendulum (L) & $1.0 \mathrm{~m}$ \\
\hline Moment of inertia of Pendulum (I) & $0.006 \mathrm{kgm}$ \\
\hline Acceleration due to gravity $(\mathrm{g})$ & $9.8 \mathrm{~m} / \mathrm{sec}^{2}$ \\
\hline Coefficient of friction $(\mathrm{b})$ & $0.1 \mathrm{~N} / \mathrm{m} / \mathrm{sec}$ \\
\hline
\end{tabular}

Table 1. Parameters of IP systems

The equations of motion are derived separately for cart and pendulum sub-systems

\section{Equations derived for Cart:}

$$
\begin{aligned}
& M \ddot{x}=\sum F \\
& F=M \ddot{x}+b \dot{x}+N \\
& \ddot{x}=\frac{1}{M}(F-N-b \dot{x})
\end{aligned}
$$

Where, $\mathrm{N}$ and $\mathrm{P}$ are the interaction forces between the cart and pendulum.

\section{Equations derived for Pendulum:}

$$
\begin{aligned}
& I \ddot{\theta}=\sum \tau \\
& \ddot{\theta}=\frac{1}{I}(N L \cos \theta+P L \sin \theta)
\end{aligned}
$$

The interaction forces $\mathrm{N}$ and $\mathrm{P}$ should also be considered in order to model complete dynamics of the system. Therefore modelling of $\mathrm{x}$ and $\mathrm{y}$ dynamics of the pendulum is done in addition to its theta dynamics. The additional $\mathrm{x}$ and $\mathrm{y}$ equations for the pendulum are given below:

$$
\begin{aligned}
& m \ddot{x}_{p}=\sum F=N \\
& m \ddot{y}_{p}=P-m g \\
& P=m\left(\ddot{y}_{p}+g\right)
\end{aligned}
$$

However $x_{p}$ and $y_{p}$ are exact functions of theta. Therefore, their derivatives are represented in terms of the derivatives of theta 


$$
\begin{aligned}
& x_{p}=x-L \sin \theta \\
& \dot{x}_{p}=\dot{x}-L \dot{\theta} \cos \theta \\
& \ddot{x}_{p}=\ddot{x}+L \dot{\theta}^{2} \sin \theta-L \ddot{\theta} \cos \theta \\
& y_{p}=L \cos \theta \\
& \dot{y}_{p}=-L \dot{\theta} \sin \theta \\
& \ddot{y}_{p}=-L \ddot{\theta} \cos \theta-L \dot{\theta}^{2} \sin \theta
\end{aligned}
$$

After substituting these equations into eq. 6 and 8, we get:

$$
\begin{aligned}
& N=m\left(\ddot{x}-L \ddot{\theta} \cos \theta+L \dot{\theta}^{2} \sin \theta\right. \\
& P=m\left(-L \dot{\theta}^{2} \cos \theta-L \ddot{\theta} \sin \theta\right)
\end{aligned}
$$

The eq. 15 and eq. 16 were used for developing, a Matlab Simulink model of IP system [24].

\section{IP SYSTEM CONTROL USING FUZZY INFERENCE CONTROLLER}

In this study two different fuzzy logic controllers(FLC) [24] were used to control the IP system. The 'FLC-1' receives Cart position and Cart velocity as inputs while Force is the output. The inputs for 'FLC-2' were Pendulum angle and Angular velocity while Force is the output. The net Force is obtained by summing the forces obtained from the both the controllers which is further used as input to Simulink of IP sub-system.

\subsection{Designing of Membership function's (MF's) for Fuzzy logic Controllers}

This study considers nine linguistic variables namely Negative Extreme(NE), Negative Big(NB), Negative Medium(NM), Negative Small(NS), Zero(ZE), Positive Small(PS), Positive Medium(PM), Positive Big(PB) and Positive Extreme(PE) for designing MF's [25] of both the controllers. A view of MF's are shown in figure 1.4 and figure 1.5. 


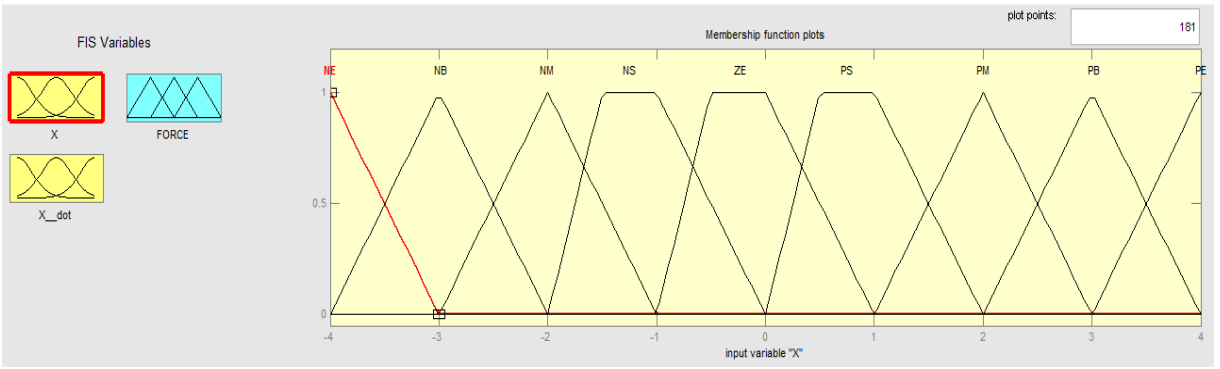

Figure 1.4 MF's of input variable 'Cart Position' for FLC-1

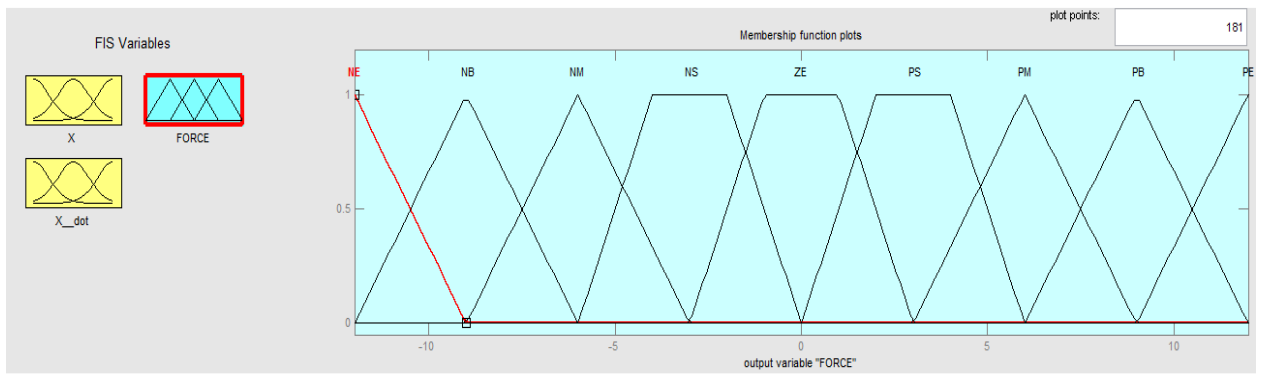

Figure 1.5 MF's of output variable 'Force' for FLC-2

\subsection{Designing of fuzzy control rules}

The fuzzy control rules for both the fuzzy controllers were designed using the experience of experts and varies from one expert to another. A view of fuzzy control rules for FLC-1 is shown in table 1.1 .

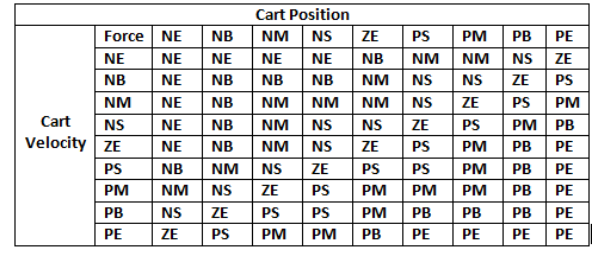

Table 1.1 Fuzzy control rules for FLC-1

Fuzzy logic toolbox allows the user to represent if-then fuzzy rules in 3-D format with the help of a Surface viewer. A 3-D view of surface viewer for FLC-1 is shown in figure 1.6

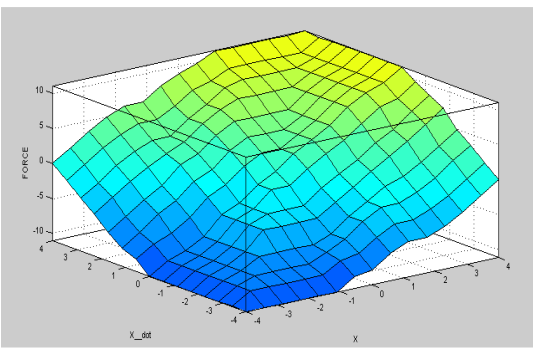

Figure 1.6 Surface Viewer for FLC-1 


\section{BUILDING SIMULINK OF IP SYSTEM}

The Simulink of IP was build in two stages. Initially a Simulink model of IP sub-system was built which was finally masked to give the complete system. A view of IP system and its sub-system are shown in figure 1.7 and figure 1.8 respectively.

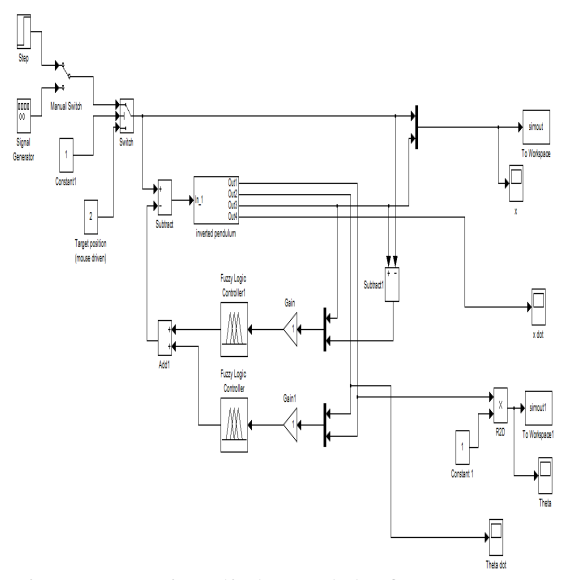

Figure 1.7 Simulink model of IP system

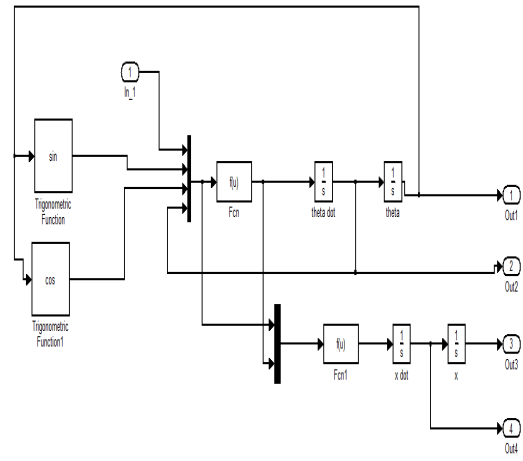

Figure 1.8 Simulink model of IP Subsystem

\section{DESIGNING OF ANFIS CONTROLLER FOR IP}

ANFIS belongs to a class of adaptive networks that combines the features of both fuzzy inference system and neural networks. ANFIS uses the learning ability of neural networks and linguistic application of fuzzy logic [26]. It performs an input output mapping based on both human knowledge (fuzzy if then rules) and on generated input output data pairs [18]. ANFIS uses a Takagi-Sugeno inference system[19], in which output of each rule can be a linear combination of input variables plus a constant term or can be only a constant term. The final output is the weighted average of each rule's output. ANFIS employs Back propagation[27] or hybrid[28] learning algorithm to optimize input data sets[20,21].

\subsection{ANFIS control of IP}

This study has considered two different data sets to train cart and pendulum controllers in ANFIS. A total of 713 data sets were collected which were further divided into training and testing data sets. The pre-designed fuzzy controller was used to generate data sets. Initially the training data was loaded from the workspace to ANFIS Toolbox and then Grid Partition method [29] was used to generate the initial FIS structure in ANFIS. A view of loading of training data sets and initial FIS generated is shown in Figure 1.9 and Figure 2.0 respectively. 
International Journal of Soft Computing, Mathematics and Control (IJSCMC), Vol. 4, No. 4, November 2015

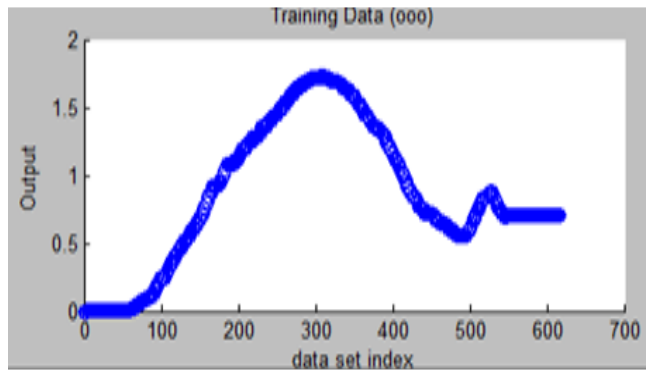

Figure 1.9 loaded training data in ANFIS

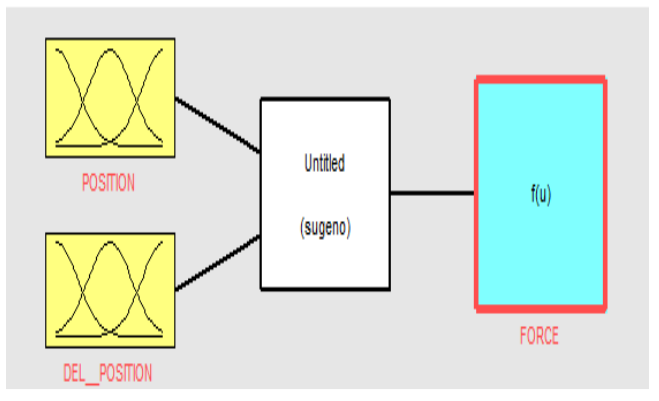

Figure 2.0 Initial FIS generated for Cart controller

The ANFIS controller uses a Takagi-Sugeno [30] inference system of 16 fuzzy if-then rules and 4 MF's. The shape of the MF's considered for input and output variables were generalized bell shape and linear respectively. A view of initial MF's before training and final MF's obtained after training are shown in figure 2.1 and figure 2.2 .

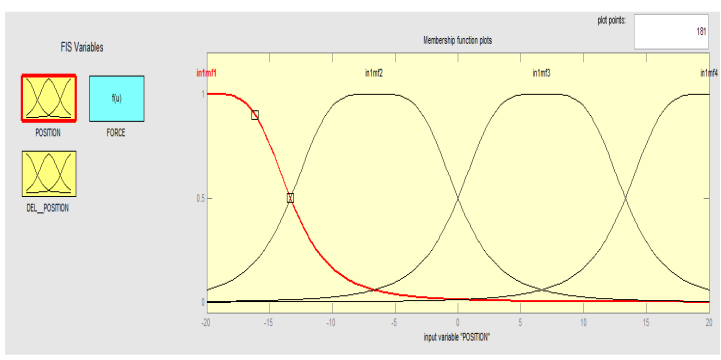

Figure 2.1 MF's before training for 'Cart Position'

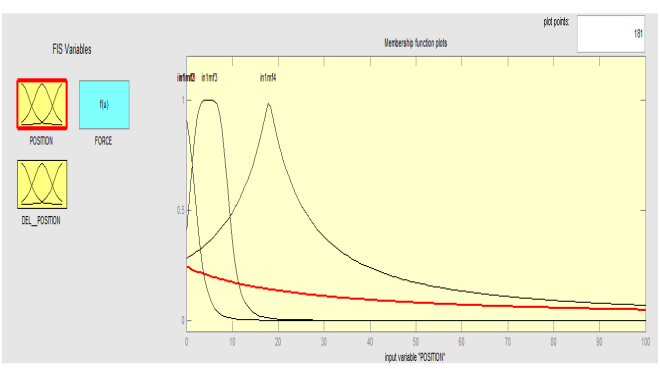

Figure 2.2 MF's after training for 'Cart Position' 
In this study a Hybrid method[22] is used to train the ANFIS controller. Hybrid method is basically a combination of Back-propagation and least square method. The error tolerance and number of epochs were set to 0 and 665 respectively. The error obtained after training is 0.003826. A view of training in ANFIS is shown in figure 2.3

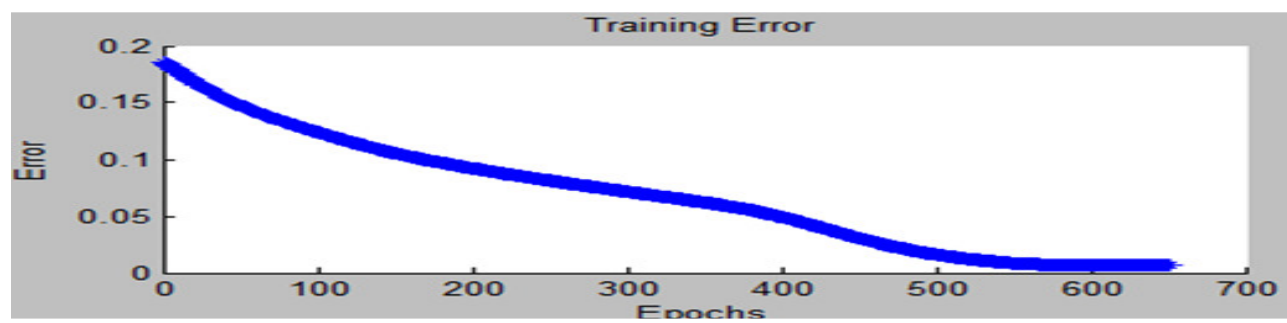

Figure 2.3 Training ANFIS controller

\section{SIMULATION RESULTS AND COMPARISON}

The Modelling and Simulation of IP system was done in Matlab-Simulink environment. A view of simulation results are illustrated from figure 2.4 to figure 2.7 .

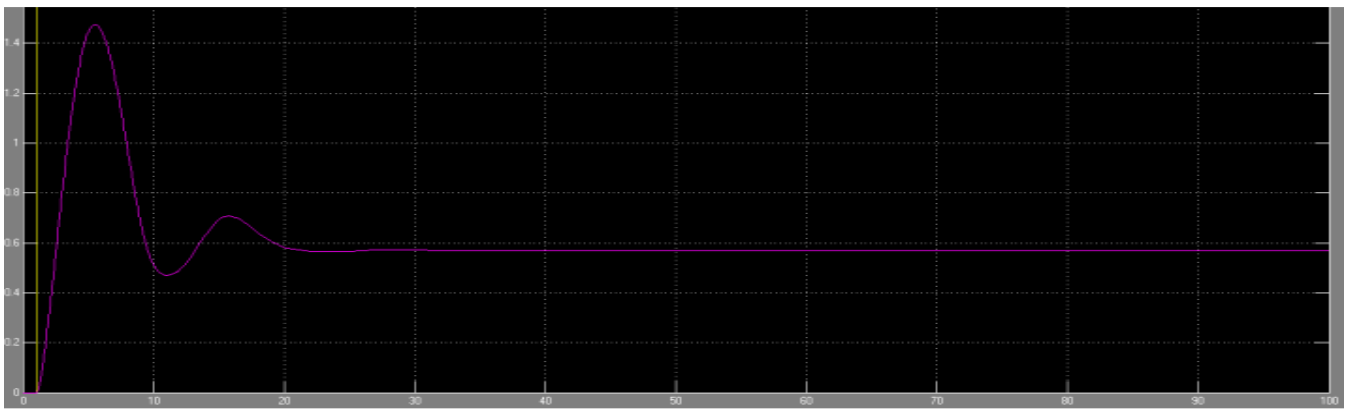

Fig 2.4 Output response of Cart Position using Fuzzy controller

\begin{tabular}{|l|c|c|}
\hline S.No & Performance Parameter & Output response \\
\hline 1 & Settling Time $(\mathrm{sec})$ & $18 \mathrm{sec}$ \\
\hline 2 & Steady state error & 0 \\
\hline 3 & Maximum Overshoot (degree) & $1.42^{\circ}$ \\
\hline
\end{tabular}

Table 1.2 Output response of Cart Position using Fuzzy controller

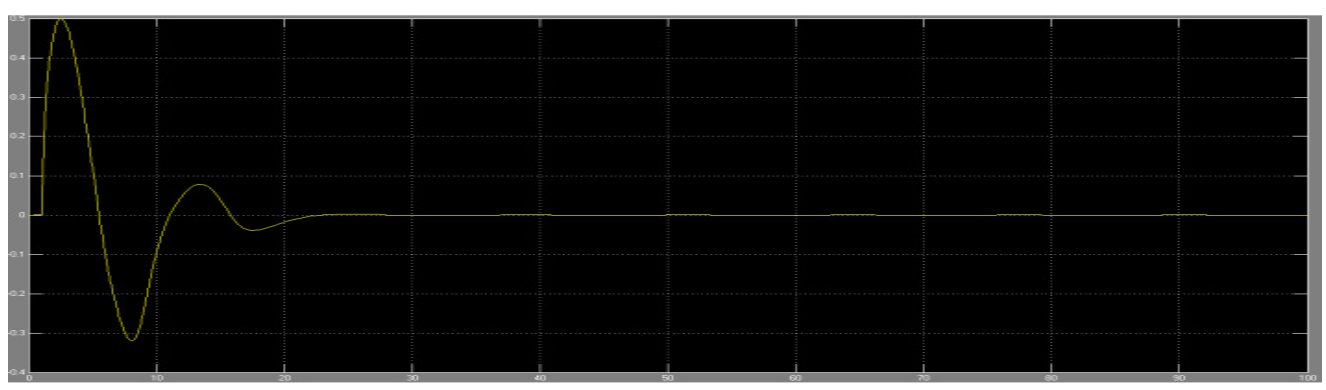

Fig 2.5 Output response of Pendulums Angular velocity using Fuzzy controller 


\begin{tabular}{|l|c|c|}
\hline S.No & Performance Parameter & Output response \\
\hline 1 & Settling Time $(\mathrm{sec})$ & $21.5 \mathrm{sec}$ \\
\hline 2 & Steady state error & 0 \\
\hline 3 & Maximum Overshoot (degree) & $0.5^{\mathbf{o}}$ \\
\hline
\end{tabular}

Table 1.3 Output response of Pendulums Angular velocity using Fuzzy controller

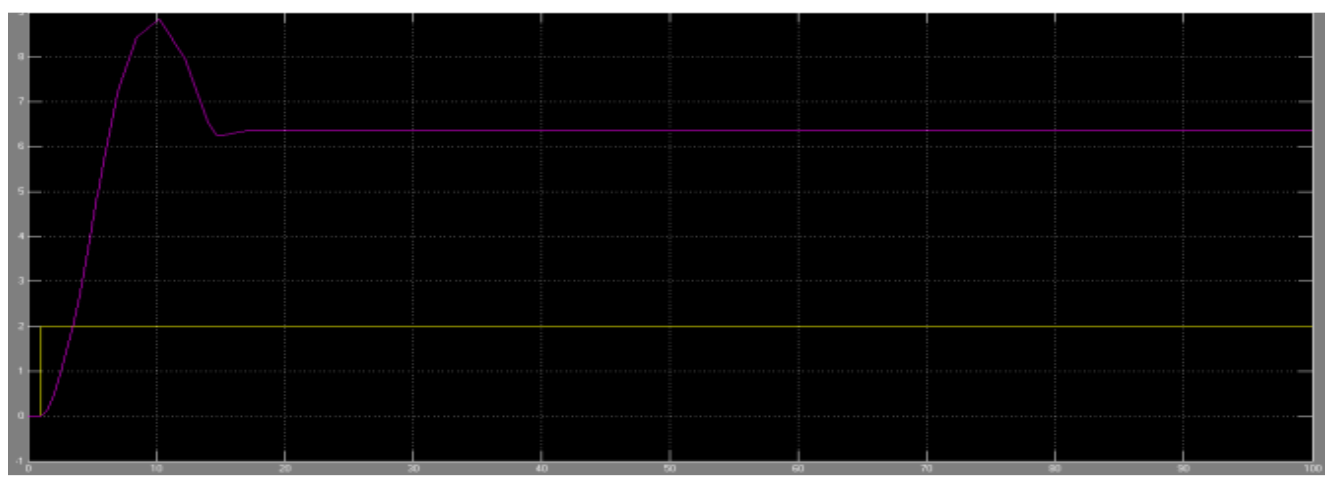

Fig 2.6 Output response for Cart Position using ANFIS Controller

\begin{tabular}{|l|c|c|}
\hline S.No & Performance Parameter & Output response \\
\hline 1 & Settling Time $(\mathrm{sec})$ & $15 \mathrm{sec}$ \\
\hline 2 & Steady state error & 0 \\
\hline 3 & Maximum Overshoot (degree) & $8.8^{\circ}$ \\
\hline
\end{tabular}

Table 1.4 Output response for Cart Position using ANFIS Controller

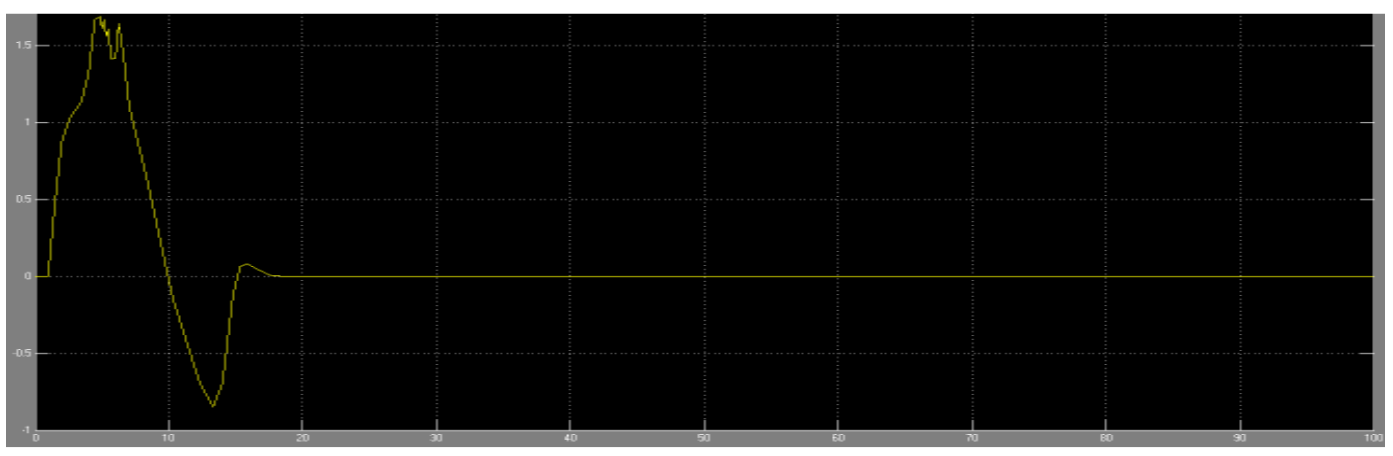

Fig 2.7 Output response of Pendulums Angular velocity using ANFIS controller

\begin{tabular}{|l|c|c|}
\hline S.No & Performance Parameter & Output response \\
\hline 1 & Settling Time $(\mathrm{sec})$ & $16 \mathrm{sec}$ \\
\hline 2 & Steady state error & 0 \\
\hline 3 & Maximum Overshoot (degree) & $1.7^{\mathbf{0}}$ \\
\hline
\end{tabular}

Table 1.5 Output response of Pendulums Angular velocity using ANFIS controller 


\section{CONCLUSION \& FUTURE RECOMMENDATIONS}

The Research objective of the study to show a comparative analysis between Fuzzy and ANFIS control of highly non-linear IP system has been achieved. The results proves the validity of proposed techniques. The results shows that the ANFIS controller provides better results as compared to Fuzzy controller. The Setting time for Cart position and Pendulum angle is reduced by $3 \mathrm{sec}$ and $5.5 \mathrm{sec}$ respectively using ANFIS controllers. It is also observed from the results that the value of maximum overshoot for both Cart and Pendulum using ANFIS controller is very large as compared to that of Fuzzy controller. Both the controllers shows an excellent response towards steady state error. The results obtained can be further refined to optimize the performance parameters specially settling time for both the controllers. Also the maximum overshoot of ANFIS controllers can be further reduced by varying values of certain attributes like training and testing data sets, MF's, training algorithm etc. As an extent to future work more Softcomputing techniques like Neural networks, Particle Swarm Optimization, Genetic Algorithm etc can also be implemented for the control of non-linear systems.

\section{REFERENCES}

[1] Kharola, A., and Gupta, P. (2013). Stabilization of Inverted Pendulum using two Fuzzy logic controllers having nine linguistic variables. International Journal of Engineering Research \& Technology(IJERT), 2(9), pp. 569-575, E-ISSN: 2278-0181.

[2] Lai, R.G. (1996). Practical feedback Stabilization of nonlinear control systems and applications. A Doctoral Thesis submitted to Department of Mathematics, Iowa State University, Ames, Iowa.

[3] Nejadfard, A., Yazdanpanah, M. \& Hassanzadeh, I. (2013). Friction compensation of double inverted pendulum on a cart using locally linear neuro-fuzzy model. Neural Computing \& Applications, 22(2), pp. 337-343.

[4] Astron, K.J. (2007). Hybrid Control of Inverted pendulums. Lecture Notes in Control and Information Sciences, 241, pp. 150-163.

[5] Ebrahim, A. \& Murphy, G.V. (2005). Adaptive backstepping controller design of an Inverted Pendulum. In Proc. of 37th IEEE Southeastern Symposium on System Theory, pp. 172-174, 20-22 March 2005.

[6] Kharola, A. \& Gupta, P. (2014). Stabilization of Inverted Pendulum using hybrid Adaptive neuro fuzzy controller. Engineering Science Letters, pp. 1-20, ISSN: 2052-5257.

[7] Hauser, J. et. al. On the driven inverted pendulum. Proceedings of the 44th IEEE Conference on Decision and Control, and the European Control Conference, (2005), pp. 6176-80.

[8] Astrom, K.J. \& Furuta, K. (2000).Swinging up a pendulum by energy control. Automatica, 36, pp. 287-295.

[9] Shiroma, N., Matsumoto, O., Kajita, S., \& Tani, K. (1996). Cooperative behavior of a wheeled inverted pendulum for object transportation. In Proc. of IEEE/RSJ International Conference on Intelligent Robot and System, pp. 390-395.

[10] Shimada, A., \& Hatakeyama, N. (2007). High-speed motion control of wheeled inverted pendulum robots. In Proc. of International Conference on Mechatronics.

[11] Zveu, K.V., Shipitko, E.A. \& Perevozchikov, A.S. (2004). Linear neural model-based predictive controller design for flexible link robot. In Proc. of International Symposium on Intelligent Control, pp. 293-298.

[12] Kuo, A.D. (2007). The six determinants of gait and the inverted pendulum analogy: A dynamic walking perspective. Human Movement Science, pp. 617-656.

[13] Vanderborght, B., Verrelst, B., VanHam, R., Damme, M.V. \& Lefeber, D. (2008). Objective locomotion parameter based inverted pendulum trajectory generator. Robotics and Autonomous Systems, pp. 738-750.

[14] Hauser, J., Saccon, A., \& Frezza, R. (2005). On the driven inverted pendulum. In Proc of 44th IEEE Conference on decision and Control, and the European Control Conference, pp. 6176-6180.

[15] Mladenov, V. (2011). Application of Neural Networks for Control of Inverted Pendulum. Wseas Transactions on Circuits and Systems, 2(10), ISSN: 1109-2734.

[16] Website - http://www.library.cmu.edu 
[17] Radhamohan, S.V., Subramaniam, M.,\& Dr Nigam, M.J. Fuzzy swing-up and stabilization of real inverted pendulum using single rule base. Journal of Theoretical and Applied Information Technology, pp. 43-48.

[18] Goswami, A. (2013). The analysis of inverted pendulum control and its other applications", Journal of Applied Mathematics \& Bioinformatics, 3(3), pp. 113-122 ISSN: 1792-6602 (print), 1792-6939 (online).

[19] Wang, H.O., Tanaka, K., \& Griffin, M.F. (1996). An Approach to Fuzzy Control of Nonlinear Systems:Stability and Design Issues. IEEE Transactions on Fuzzy Systems,4, pp.14-23, doi:10636706/ 96/ IEEE.

[20] Wahida Banu.R.S.D, ShakilaBanu.A and Manoj.D. (2011). Identification and Control of Nonlinear Systems using Soft Computing Techniques. International Journal of Modeling and Optimization, 1(1), pp. 24-28.

[21] Li, B., \& Chen, T. (2007). The Control of the Inverted Pendulum Based on Adaptive Neural-Fuzzy Inference System. Microsoft Information, 23, pp.27-29, doi:1008-0570(2007)08-1-0027-02

[22] Qiang, S., Zhou, Q., Gao, X.Z., \& Yu, S. (2008). ANFIS Controller for Double Inverted Pendulum. In Proc. of IEEE International Conference on Industrial Informatics, July 2008, pp. 475-479, 978-14244-2171-8/08/IEEE.2008

[23] Srivastava, M.K. (2009). Analysis of Control of Inverted Pendulum using Adaptive neuro fuzzy system. A Master Thesis submitted to Department of Electronic Instrumentation and Control Engineering, Thapar University, Patiala, Punjab.

[24] Lee, C.C. (1990). Fuzzy logic in Control Systems: Fuzzy logic controller-Part I. IEEE Transactions on System, Man \& Cybernetics, 20(2), pp. 404-418.

[25] Hang, T.P., \& Lee, C.Y. (1996). Induction of fuzzy rules and membership functions from training examples. Fuzzy Sets and Systems,84, pp. 33-47.

[26] Jang, J.S.R. (1993). ANFIS: Adaptive Network based fuzzy Inference System. IEEE Transaction on Systems, Man \& Cybernetic,23(3), pp. 665-685

[27] Li, J., Cheng, J., Shi, J., \& Huang, F. (2012). Brief Introduction of Back Propagation (BP). Neural Network Algorithm and its improvement in Intelligent and Soft Computing, 169, pp. 553-558.

[28] Yong, X. (2012). Research on Control of System of Hybrid learning Algorithm of Fuzzy Neural Network. Journal of Convergence Information Technology (JCIT), 7(18), pp. 372-382.

[29] Jang, J.S.R., \& Sun, C.T. (1995). Neuro-fuzzy modeling and control. In Proc. of IEEE, 83(3), pp. 378-406.

[30] Mehran, K. (2008). Takagi-Sugeno fuzzy modeling for Process control. A report submitted to school of Electrical, Electronic and Computer Engineering, Newcastle University.

\section{Authors}

Ashwani Kharola received B.Tech (Honours) in Mechanical Engineering from Dehradun Institute of Technology, Dehradun in 2010 and M.Tech in CAD/CAM \& Robotics from Graphic Era University, Dehradun in 2013. He obtained Silver Medal in M.Tech for (2011-13) batch. Currently he is working as Senior Research Fellow (SRF) in Institute of Technology Management (ITM), One of premier training institute of Defence Research \& Development Organisation (DRDO), Ministry of Defence, Govt.

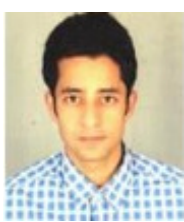
of India. $\mathrm{He}$ is also pursuing $\mathrm{PhD}$ in Mechanical Engineering from Graphic Era University. He has published more than 16 National/International papers in peer reviewed ISSN Journals and IEEE Conferences. His current areas of work includes Fuzzy logic reasoning, Adaptive Neuro-fuzzy inference system (ANFIS) control, Neural Networks, Mathematical Modeling \& Simulation, etc. 